\title{
Towards more sustainable and environmentally-friendly concretes: the use of silica fume
}

\author{
A. Kanellopoulos, I. Ioannou \& M. F. Petrou \\ Department of Civil and Environmental Engineering, \\ University of Cyprus, Cyprus
}

\begin{abstract}
Concrete is the most widely used construction material. At the same time, however, the concrete industry is a major $\mathrm{CO}_{2}$ emitter thus contributing towards global warming. While enhanced efficiency in the production of concrete is not likely to dramatically reduce the $\mathrm{CO}_{2}$ emissions, cement replacement by a supplementary material or mineral additive, such as silica fume, which is not associated with $\mathrm{CO}_{2}$ emission, can substantially reduce the aforementioned problem. The present work discusses the benefits of incorporating mineral additives in concrete and shows that these additives can improve both the mechanical and physical properties of the end-product, and hence its durability, albeit with a reduction in cement content.
\end{abstract}

Keywords: mineral additives, concrete, sustainability, durability, mechanical properties.

\section{Introduction}

Concrete is the most widely used construction material with annual production exceeding 6.4 billion cubic metres [1]. At the same time, however, the concrete industry is a major $\mathrm{CO}_{2}$ emitter thus contributing towards global warming. The production of cement alone contributes about $5 \%$ to the global anthropogenic $\mathrm{CO}_{2}$ emissions [2]. The average intensity of $\mathrm{CO}_{2}$ emissions from total global cement production is $222 \mathrm{~kg}$ per ton of cement. In terms of conventional concrete mixtures, this is equivalent to more than $100 \mathrm{~kg}$ of $\mathrm{CO}_{2}$ emissions per cubic metre of concrete. While enhanced efficiency in the production of concrete 
is not likely to dramatically improve these numbers, cement replacement by a supplementary material or mineral additive, such as silica fume, which is not associated with $\mathrm{CO}_{2}$ emission, can substantially reduce the aforementioned problem.

In Cyprus, utilization of mineral additives in concrete mixtures is practically non-existent. Contractors and ready-mixed concrete plant owners avoid incorporating them in their mix designs because they focus on minimizing their production costs. However, there is a demand from the European Union for a substantial reduction of $\mathrm{CO}_{2}$ emissions in the next few years. Therefore, the local concrete industry faces the challenge of producing more environmentallyfriendly mixtures, while at the same time maintaining their quality.

This paper discusses some preliminary results from experiments that were undertaken in the Laboratory of Building Materials at the Department of Civil and Environmental Engineering of the University of Cyprus. The experimental work aimed at producing high quality concrete with the use of mineral additives. The ultimate objective of the work, which is still in progress, is to illustrate to the local concrete industry that the production of high quality environmentally friendly concrete is a feasible option in Cyprus.

\section{Experimental work}

The concrete mixtures presented in this study were prepared with standard CEMII $52.5 \mathrm{~N}$ grade cement (specific gravity, s.g. $=3.15$ ), coarse diabase aggregates in two different particle size gradings $(8-20 \mathrm{~mm}$ and $4-10 \mathrm{~mm})$ and two types of fine calcareous aggregates of particle size $0-4 \mathrm{~mm}$ and $0-2 \mathrm{~mm}$ respectively. Additionally, silica fume $\left(94 \%\right.$ in $\mathrm{SiO}_{2}-$ s.g. $\left.=2.20\right)$ was used as a cement replacement, whereas poly-naphthalene condensates were used in order to reduce the mix water. Prior to mix design, the aggregates were examined in the laboratory in order to determine their moisture content and water absorption (Table 1).

Table 1: Moisture content and water absorption values for aggregates utilized in the experimental program.

\begin{tabular}{|l|c|c|}
\hline & $\begin{array}{c}\text { Moisture } \\
\text { Content } \\
(\%)\end{array}$ & $\begin{array}{c}\text { Water Absorption } \\
(\%)\end{array}$ \\
\hline Coarse Diabase $8 / 20 \mathrm{~mm}$ & 0.5 & 2.5 \\
\hline Coarse Diabase $4 / 10 \mathrm{~mm}$ & 0.6 & 3.7 \\
\hline Limestone Sand 0/4 mm & 0.6 & 1.7 \\
\hline Fine Sand mm & 0.7 & 2.0 \\
\hline
\end{tabular}


All mixtures were designed as typical high-strength concrete mixtures (Table 2). Three of them (M1, M3 and M5) did not contain mineral additive and replicated mixtures currently used in the local construction industry, whereas mixtures M3, M4 and M6 were designed by partially replacing the cement of the parent mixtures with silica fume. The cement replacements were $12 \%$ by volume for M1, $11 \%$ by volume for M3 and 13\% by volume for M5. For each pair of mixtures, the water content was modified accordingly in order for the mixtures to have the same water to binder ratio $(\mathrm{w} / \mathrm{b})$. It is worth noting that the term binder is used to define the total quantity of cement and silica fume. In other words, for the mixtures without the cement replacement material, the $\mathrm{w} / \mathrm{b}$ equals the water to cement ratio $(\mathrm{w} / \mathrm{c})$.

In order to obtain the mechanical properties of the mixtures, cubic specimens $(150 \times 150 \times 150 \mathrm{~mm})$, cylinders $(150 \times 300 \mathrm{~mm})$ and beams $(100 \times 100 \times 500 \mathrm{~mm})$ were cast. All cubic and cylindrical specimens were tested on a $5000 \mathrm{kN}$ compression frame for the evaluation of their compressive strength, and modulus of elasticity. Prismatic specimens were tested on a $100 \mathrm{kN}$ flexural frame, under a three-point bend test, to obtain their flexural strength.

Table 2: $\quad$ Concrete mixtures with and without silica fume.

\begin{tabular}{|c|c|c|c|c|c|c|c|}
\hline & & M1 & M2 & M3 & M4 & M5 & M6 \\
\hline Cement $-52.5 \mathrm{~N}$ & $\mathrm{~kg} / \mathrm{m}^{3}$ & 475 & 400 & 500 & 410 & 500 & 450 \\
\hline Silica Fume & $\mathrm{kg} / \mathrm{m}^{3}$ & - & 40 & - & 40 & - & 45 \\
\hline $\begin{array}{c}\text { Coarse Diabase } \\
8 / 20 \mathrm{~mm}\end{array}$ & $\mathrm{~kg} / \mathrm{m}^{3}$ & 706 & 680 & 708 & 680 & 708 & 680 \\
\hline $\begin{array}{c}\text { Coarse Diabase } \\
4 / 10 \mathrm{~mm}\end{array}$ & $\mathrm{~kg} / \mathrm{m}^{3}$ & 233 & 275 & 233 & 270 & 233 & 280 \\
\hline $\begin{array}{c}\text { Limestone Sand I } \\
0 / 4 \mathrm{~mm}\end{array}$ & $\mathrm{~kg} / \mathrm{m}^{3}$ & 543 & 560 & 533 & 540 & 533 & 550 \\
\hline $\begin{array}{c}\text { Limestone Sand II } \\
0 / 2 \mathrm{~mm}\end{array}$ & $\mathrm{~kg} / \mathrm{m}^{3}$ & 134 & 110 & 131 & 130 & 131 & 140 \\
\hline Water & $\mathrm{kg} / \mathrm{m}^{3}$ & 214 & 200 & 210 & 190 & 210 & 210 \\
\hline $\begin{array}{c}\text { Superplasticiser } \\
\mathrm{lt} / \mathrm{m}^{3}\end{array}$ & 4 & 3.7 & 4 & 2.9 & 2 & 1.9 \\
\hline w/c & - & 0.45 & 0.50 & 0.42 & 0.46 & 0.42 & 0.47 \\
\hline w/b & - & - & 0.45 & - & 0.42 & - & 0.42 \\
\hline
\end{tabular}


Experiments were also conducted on cylindrical cores $(37 \mathrm{~mm}$ in diameter and $90 \mathrm{~mm}$ height) taken from the cubic specimens, in order to determine their vacuum saturation open porosity and capillary absorption (sorptivity). The methodologies for these two tests are described in detail in [3]. In both cases, propanol was used as the wetting liquid in order to avoid any possible reaction between water and the remaining unhydrated material in the specimens.

\section{Results and discussion}

The experimental results of the tests undertaken in order to determine the physico-mechanical properties of the hardened concrete samples are summarised in Table 3.

From the results it is obvious that, besides the expected increase in compressive strength due to the mineral addition, an improvement is also observed in the two durability indicators (porosity and sorptivity). A $12 \%$ by volume cement replacement in M2 resulted in a substantial $27 \%$ reduction in the porosity and $29 \%$ reduction in the sorptivity of the concrete mixtures. The same trend was observed in the second set of mixtures where the introduction of silica fume into the mix reduced the porosity by $12 \%$ and the sorptivity by $29 \%$. Similar results were observed for mixtures M5 and M6; the mineral admixture reduced the porosity by $13 \%$ and the sorptivity by $33 \%$.

It is therefore obvious that the use of silica fume mineral additive as partial cement replacement in concrete has resulted in mixtures that have a dense homogeneous microstructure, which in turn has led to better mechanical performance and improved durability.

Table 3: Experimental results for concrete mixtures with and without a mineral additive ( $f_{\mathrm{cu}}$ : compressive strength; E-Value: Modulus of Elasticity).

\begin{tabular}{|c|c|c|c|c|c|c|c|}
\hline & & M1 & M2 & M3 & M4 & M5 & M6 \\
\hline 28-days $\mathrm{f}_{\mathrm{cu}}$ & $\mathrm{MPa}$ & 61.7 & 73.2 & 66.9 & 73.3 & 67.5 & 68.5 \\
\hline $\begin{array}{l}\text { Flexural } \\
\text { Strength }\end{array}$ & $\mathrm{MPa}$ & 4.7 & 6.5 & 6.5 & 7.2 & 6.8 & 7.3 \\
\hline E-Value & $\mathrm{GPa}$ & 26 & 28 & 27 & 29 & 28 & 29 \\
\hline Porosity & $\%$ & 17.5 & 12.7 & 14.8 & 13.1 & 13.9 & 12.1 \\
\hline Sorptivity & $\mathrm{mm} / \mathrm{min}^{1 / 2}$ & 0.07 & 0.05 & 0.07 & 0.05 & 0.06 & 0.04 \\
\hline
\end{tabular}


Regarding durability, it is worth noting that the decrease in porosity and sorptivity values observed during this study has direct implications on the watermediated deterioration factors of concrete, such as freeze-thaw and salt crystallisation, as well as on alkali-silica reactions which contribute towards the deterioration of concrete structures. These processes can be avoided if concrete permeability and water ingress are reduced. Concretes with low porosities and sorptivities are likely to allow less water through them and therefore they are expected to behave better when exposed to the environmental conditions.

One should note that even though the design of concrete structures to-date is mainly done on the basis of concrete 28-day compressive strength, the durability of the material is equally important. While the mechanical strength enables engineers to design safe structures, we also need to ensure that concrete will maintain its strength throughout the useful life of the structure. In many cases, this is not feasible because exposure to environmental conditions causes poor quality concrete to lose its functionality. As a result, many structures have to be demolished long before the end of their useful life. This leads to major socioeconomic and environmental issues.

The results of the present study show that mineral by-products can offer alternative viable solutions to the concrete industry in its attempt to face the quality issues associated with concrete mixtures. However, a framework, at least at national level, to encourage research on this particular subject and shift the interest of manufacturers, engineers and end-users on environmental awareness is needed. While profit may still be the main target, it should become clear that this may be achieved by creating more durable structures and by protecting our environment.

\section{Conclusions}

The concept of sustainable development in concrete technology is not a trend but rather a vital policy that will last and become even more important in the future, since the viability of cement and concrete industries strongly depends on it. It is therefore essential for these industries to find ways of reducing $\mathrm{CO}_{2}$ emissions in their production lines. At the same time, it is essential for engineers to learn how to incorporate ecological and socioeconomic costs when evaluating a given project. Taking all that into consideration, modern types of concretes (such as high performance concretes with the use of mineral additives) will become the norm. The cost of the latter is not much higher compared to conventional concretes, especially when one takes into account their improved performance and durability.

The results of the study presented in this paper show that sustainable concepts can offer valuable solutions in the quest for environmentally friendly concrete in Cyprus. The exploitation of mineral additives in concrete mixes has resulted in good quality concrete with improved durability indicators. Further research in the field is likely to highlight more advantages of mineral additives, while the application of the mixes prepared in the laboratory in real life projects is expected to convince the producers and end-users that the cost is not high. 
270 Sustainable Development and Planning IV, Vol. 1

\section{References}

[1] Aitcin P.C. Cements of yesterday and today - Concrete of tomorrow. Cement and Concrete Research 30, 2000, pp. 1349-1359.

[2] Worell, E, Price, L, Hendricks, C \& Ozawa Meida, L., Carbon dioxide emissions from the global cement industry, Annual Review of Energy and Environment, 26, pp. 303-329, 2001.

[3] Gummerson, R.J., Hall, C. \& Hoff, W.D. 1980. Water movement in porous building materials - II. Hydraulic suction and sorptivity of brick and other masonry materials. Building and Environment 15(2): 101-108. 